\title{
Selection of inhibited preservative materials for corrosion protection of gage parts (level transmitter torque tubes in primary and secondary oil processing units) and experience in application of such materials
}

\author{
V. V. Burlov, T. P. Parputs and E. A. Tronova \\ OOO NPO NEPhTEKhIM, ul. Pulkovskaya 10, St. Petersburg, \\ 196158 Russian Federation.E-mail:t.parputs@yandex.ru
}

\begin{abstract}
The reasons of initiation and development of local corrosion attack which is the most hazardous form of destruction of thin-walled tubes in level transmitters at oil processing units are examined. The protective effect of oil-based preservation materials with respect to nickel and copper-nickel alloys in hydrocarbon media containing chlorides and sulfur compounds has been studied. Laboratory studies and industrial tests have shown that the highest protective effect is provided by M-1 inhibitor at 5 mass\% concentration in PES-5 silicone oil. The formulation is successfully used for the protection of torque tubes in liquid level transmitters at primary and secondary oil processing units.
\end{abstract}

Key words: corrosion, level transmitter torque tubes, stagnant zones, preservative formulations, M-1 inhibitor, PES-5 silicone oil, nickel and copper-nickel alloys, oil processing environments.

Received: April 19, 2013.

doi: $\underline{10.17675 / 2305-6894-2013-2-3-231-244}$

Corrosion of equipment and various units at refineries is a major problem and one of the most important factors determining the duration of trouble-free process equipment operation. As worldwide practice shows, particular attention is given today to the corrosion and diminishing the corrosion wear of the metal in the core oil processing equipment. However, despite the considerable progress in corrosion protection at refineries, issues of the corrosion and protection of certain devices integrated in the core equipment in order to monitor and control the process technology remain unstudied.

When choosing a structural material to provide the guaranteed operation of petrochemical plants for a long inter-repair period, main attention must be given to the character of the corrosive environment, process conditions, and equipment design. In many cases, inaccurate material selection and poor design can decrease the inter-repair period, increase equipment downtime, or even result in a failure.

In recent years, the use of nickel alloys in oil processing and oil chemistry processes started, though they are expensive. This is caused by the high corrosion resistance of such materials, both under atmospheric conditions and at high temperatures, in many corrosive media, especially in acidic ones. The corrosion properties of nickel and its alloys are 
largely due to their relatively high thermodynamic stability in oxidizing media. Of various nickel-based alloys, it is alloys doped with copper, chromium, molybdenum, and silicon that are most interesting from the practical point of view [1].

However, data are available that nickel alloys (e.g., Monel) have insufficient corrosion resistance and even tend to undergo intergranular corrosion and pitting in hydrocarbon media containing sulfur compounds [2]. In view of this, the use of nickel alloys in refinery equipment requires a thorough consideration of all factors that affect the corrosion resistance of structural materials and process instrumentation.

Early failures of instrumentation, liquid level transmitters in particular, decrease the inter-repair period and downtime of columns and vessels in general. In fact, over ten years of operation (from 2000 to 2010), corrosion resulted in repeated failures of torque tubes in 12300 series liquid level transmitters (TsDU-01) manufactured by Dresser Masoneilan that were operated in various primary and secondary oil processing units.

The level transmitter torque tubes are $0.6 \mathrm{~mm}$ thick and are made of various highnickel materials: Hastelloy C276, Inconel 600, and Monel 400. Despite their high corrosion resistance in corrosive oil processing environments, the life time of tubes until degradation ranged from two to six years.

The chemical composition of the high-nickel alloys in the tubes studied mostly meets the requirements of ASTM B168 standard for Inconel 600, ASTM B 574 standard for Hastelloy C276, and ASTM B127 standard for Monel 400. However, some samples of Hastelloy tubes have a higher carbon content of 0.04 mass $\%$ rather than 0.01 mass $\%$ according to ASTM B 574. If the alloy contains an increased amount of carbon, it is susceptible to intergranular corrosion (IGC) and pitting [3].

Studies of numerous failure cases of torque tubes have shown that destruction occurs nearly in all types of process units and that the level transmitter design is among the most significant factors that affect the corrosion process.

Figure 1 shows a scheme of a 12300 series (TsDU-01) liquid level transmitter (manufactured by Dresser Masoneilan) acting by the "displacer-torque tube" principle. A change in the liquid level varies the displacer weight, thus increasing or decreasing the stress on the torque tube, with its subsequent rotation resulting in bending torsional stress. As a result, torque tubes operate under high stress conditions (rotation torque) favoring the formation of a "fresh" metal surface (a surface not protected with an oxide film). It is more anodic and the action of the corrosive environment on it becomes more intense, hence corrosion is accelerated. Acceleration of the corrosion process results in more mechanical damage and thus in acceleration in the crack propagation rate owing to the joint effect of the corrosive environment and tensile stress [4].

A specific design feature of level transmitters is that they comprise a natural air gap between the torque tube and its chamber, which results in stagnant zones. As corrosive process liquids enter these zones, they can undergo condensation accompanied by concentrating of corrosive components on the tube surfaces, thus increasing the corrosivity of electrolytes. 


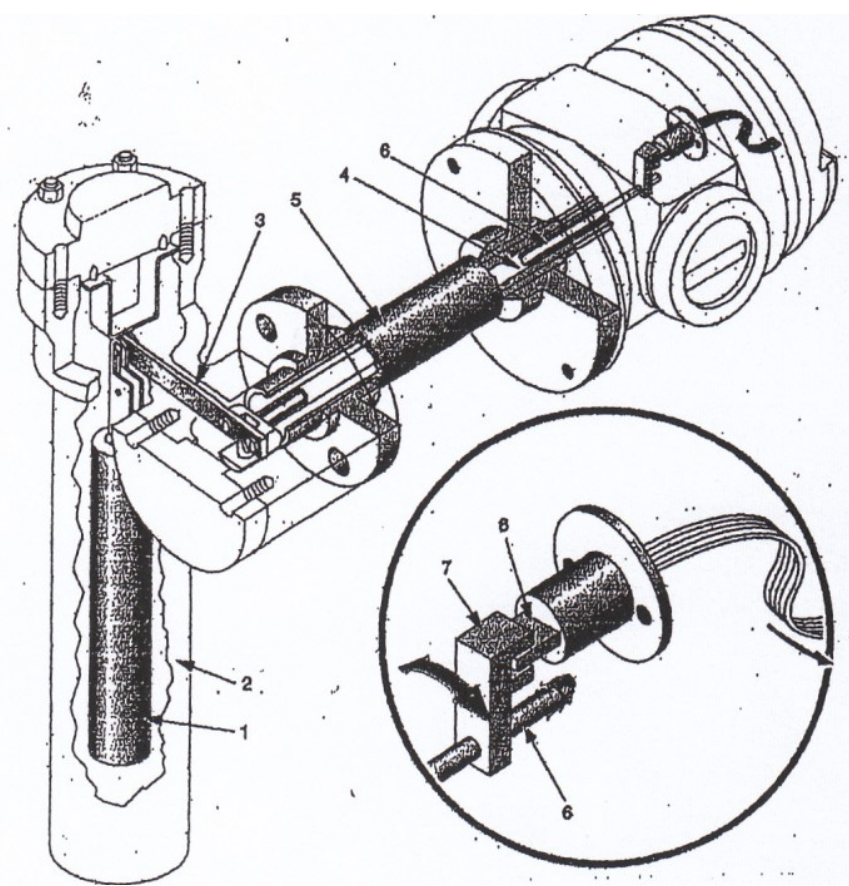

Fig. 1. Scheme of a Masoneilan 12300 series level transmitter (TsDU-01): 1, displacer;

2, displacer chamber; 3 , torque arm; 4 , torque tube; 5 , torque tube housing; 6 , torque rod;

7, magnets; 8 , Hall effect sensor.

Our systematic studies on the process fluids of core oil processing equipment have shown that their corrosivity under operation conditions of the units is primarily determined by chlorine- and sulfur-containing compounds. The corrosivity of environments in a level transmitter chamber is governed by the components present in the process fluid of a particular vessel where the level transmitter is installed. Considering the design feature of level transmitters characterised by the existence of a stagnant zone, it is quite reasonable to believe that the corrosivity of the fluid in the level transmitter chamber would be somewhat higher than in the core equipment, which may favor the intensification of the corrosion processes on the torque tube metal.

The corrosion resistance of the metal in the equipment and its structural parts under oil processing conditions is determined by the combined effect of the environments formed at various stages of unit operation: in operation mode, during steam treatment, and during equipment downtimes [5]. As an example, Table 1 presents the results of studies on the corrosivity of process fluids in some vessels of oil refinery units.

The oil processing fluids that contact equipment, including the level transmitter torque tubes, vary in corrosivity. The composition and concentrations of corrosive components in process media at different stages of equipment operation depend on the process technology, composition and quality of process environments, quality of the oils being processed, degree of oil desalination, thermal stability of organochlorine and organosulfur compounds, frequency of equipment steam treatment and downtime periods, and the degree of solution concentration increase in stagnant zones as well as for miscellaneous other reasons. 
Steam treatment of equipment with level transmitters can be accompanied by ingress of corrosive vapors of steam treatment condensates into the level transmitter case. Specific features of level transmitter design prevent the removal of deposits from the tube surface, so the metal undergoes considerable corrosion on exposure to humid deposits. Furthermore, when equipment is shut down for repairs, corrosion products (FeS, NiS) undergo oxidation by moisture and oxygen to give additional corrosive components, such as polythionic acids and thiosulfates, sulfates, and elementary sulfur that initiate local corrosion. This follows from the results of numerous studies on deposit composition. For instance, the deposits on the outside surface of a torque tube in a level transmitter installed in the stabilization column of a diesel fuel hydrotreatment unit contain the following components: 2.6 mass $\% \mathrm{SO}_{4}^{2-} ; 6.7$ mass $\% \mathrm{~S}^{2-} ; 0.2$ mass $\% \mathrm{Cl}^{-} ; 49.0$ mass $\% \mathrm{Fe}_{\text {total }}$; up to $1 \%$ elementary sulfur. Elementary sulfur may be result from cathodic reduction of thiosulfate ions.

Visual optical examination of outside tube surfaces showed that the metal underwent pitting and corrosion cracking. Local corrosion was mainly observed in Inconel 600 tubes, in agreement with literature data that the corrosion resistance of Hastelloy C-276 $(02 \mathrm{Kh} 16 \mathrm{~N} 60 \mathrm{M} 16 \mathrm{~V})$ and Monel is higher than that of Inconel in chlorine- and sulfurcontaining environments, including polythionates and thiosulfates [6].

Table 1. List of level transmitters installed in Kirishi refinery units, indicating the location, operating conditions, and results of metallographic examination.

\section{Location of level Operation conditions; process transmitter fluid corrosivity under various operation modes of equipment \\ Material $\begin{gathered}\text { Service, Metallography results } \\ \text { years }\end{gathered}$}

$$
\begin{gathered}
\text { Operation mode: } \\
P=12-14 \mathrm{~kg} / \mathrm{cm}^{2}, \\
T=230-250^{\circ} \mathrm{C} .
\end{gathered}
$$

Fluid: gasoline fractions $100-180^{\circ} \mathrm{C}$

Preliminary containing up to $0.001 \mathrm{mass} \%$ total hydrotreatment sulfur, traces of hydrogen sulfide, in a reforming unit and $4 \mathrm{mg} / \mathrm{l}$ chlorides with $1 \mathrm{mln}$ tons per year feed capacity

\section{Steam treatment:} Aqueous condensate: $\mathrm{pH} 4.26$, $\left[\mathrm{Cl}^{-}\right]=7597 \mathrm{mg} / \mathrm{l}$, $\left[\mathrm{SO}_{4}^{2-}\right]=4.3 \mathrm{mg} / \mathrm{l}$

Downtime: deposits, $\mathrm{pH}_{\text {aq. extract }}=$ $4.9,\left[\mathrm{Cl}^{-}\right]=0.66$ mass $\%,\left[\mathrm{SO}_{4}^{2-}\right]=$ $2.7 \mathrm{mass} \%,\left[\mathrm{~S}^{2-}\right]=21.8 \mathrm{mass} \%$, moisture, atmospheric oxygen.

\begin{tabular}{cccc}
\hline $\begin{array}{c}\text { Preliminary } \\
\text { hydrotreatment }\end{array}$ & $\begin{array}{c}\text { Operation mode: } \\
P=12-14 \mathrm{~kg} / \mathrm{cm}^{2}, \\
\text { in a reforming unit }\end{array}$ & $T=230-250^{\circ} \mathrm{C}$.
\end{tabular}$\quad$ Inconel $6 \begin{gathered}\text { Intergranular corrosion } \\
\text { through-cracking (ICC), } \\
\text { grain size }=5 \text { units }\end{gathered}$




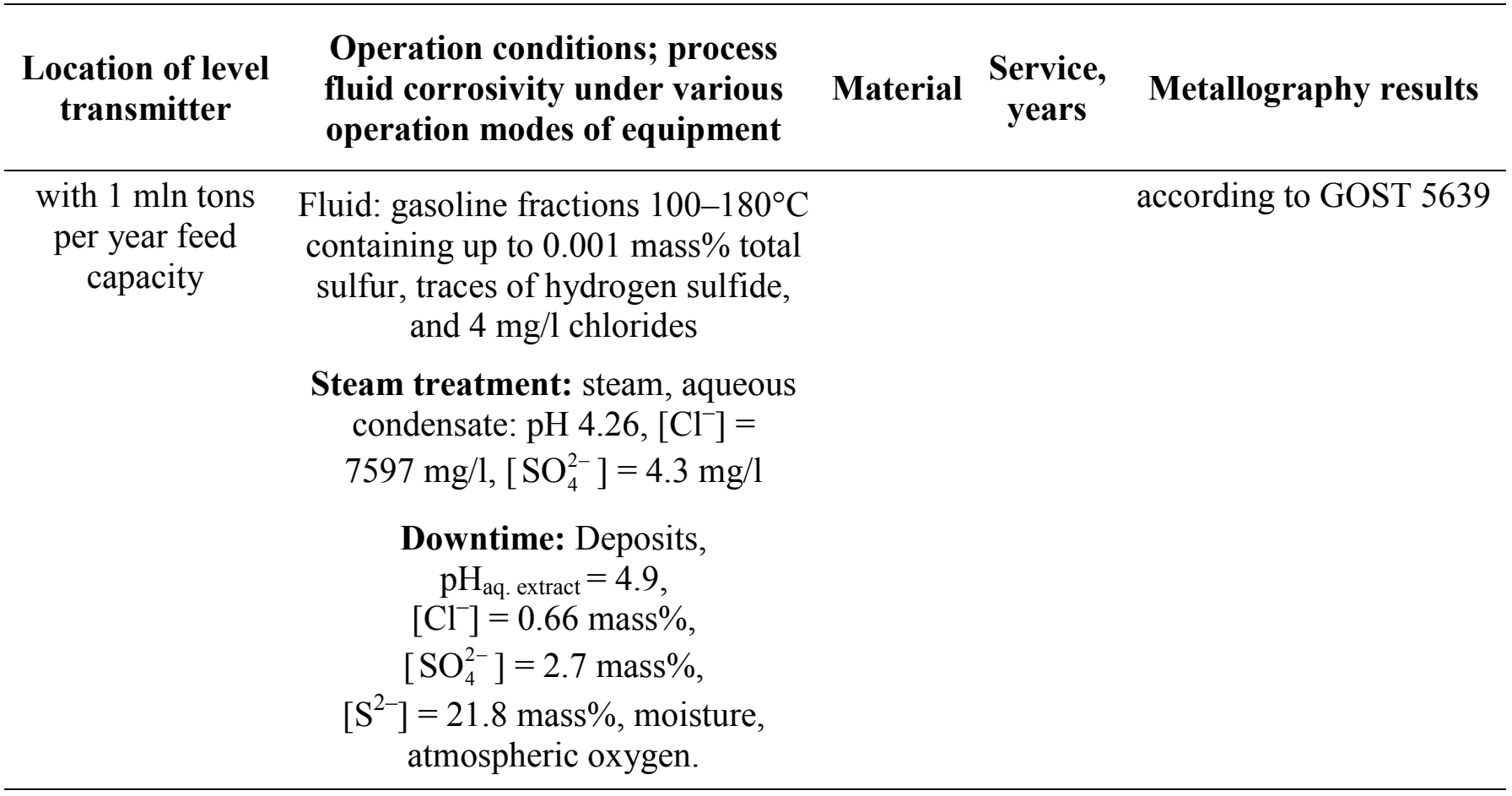

Operation mode: $P=20 \mathrm{mmHg}$,

$$
T=350^{\circ} \mathrm{C} \text {. }
$$

Fluid: tar containing up to 2.0 mass $\%$ total sulfur, $\left[\mathrm{Cl}^{-}\right]=0.003$ mass $\%$.

Gasoline afterfractionating column at a crude oil distillation plant with $6 \mathrm{mln}$ tons capacity
Steam treatment: steam, condensate: $\mathrm{pH} 6.1$, $\left[\mathrm{Cl}^{\top}\right]=37.0 \mathrm{mg} / 1$, $\left[\mathrm{SO}_{4}^{2-}\right]=133 \mathrm{mg} / 1$

Inconel 4

Downtime: Atmospheric moisture, atmospheric oxygen, deposits:

$$
\begin{gathered}
\mathrm{pH}_{\text {aq. extract }}=3.43, \\
{\left[\mathrm{~S}_{\text {total }}\right]=1.28 \text { mass } \%} \\
{\left[\mathrm{SO}_{4}^{2-}\right]=2.12 \text { mass } \%,}
\end{gathered}
$$

$\left[\mathrm{Cl}^{-}\right]-$traces
Intergranular corrosion through-cracking (ICC), grain size $=4$ units according to GOST 5639

\section{Operation mode:}

\section{Stabilizer column of a diesel fuel hydrotreatment plant}

$$
\begin{gathered}
T_{\text {top }}=120^{\circ} \mathrm{C}, \\
T_{\text {bottom }}=230^{\circ} \mathrm{C}, \\
P=1.4 \mathrm{~kg} / \mathrm{cm}^{2} .
\end{gathered}
$$

Environments: Top: Gasoline, Inconel 5 water vapors hydrocarbon gas containing up to 12 vol. \% hydrogen sulfide.
Pits up to $0.236 \mathrm{~mm}$ Grain size $=6$ units according to GOST 5639s 


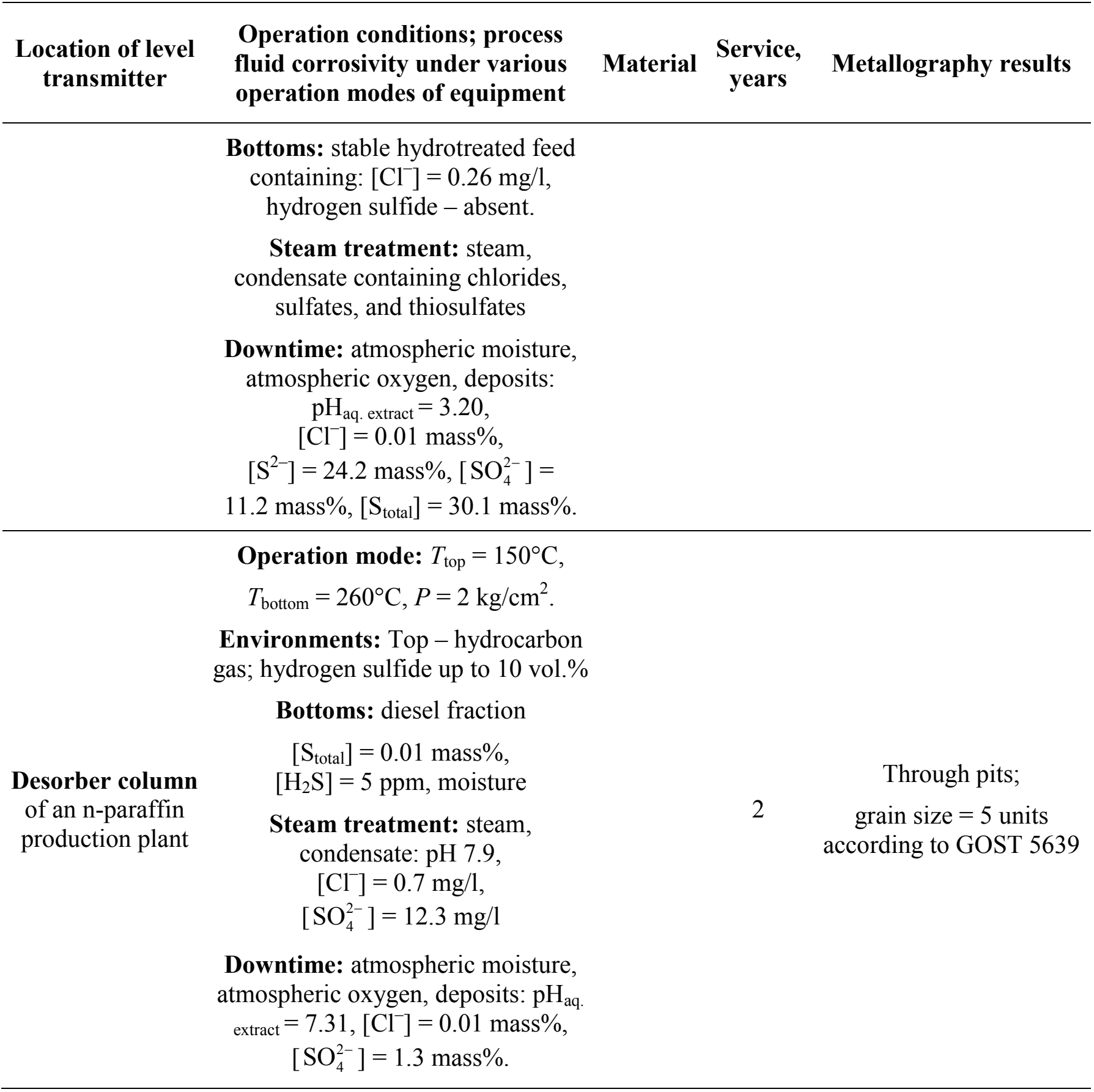

In order to estimate the structural state and determine the nature and degree of failure, we performed a metallographic analysis of torque tube samples. Samples of torque tubes (Fig. 2) from various materials (Hastelloy C-276, Inconel 600, and Monel 400) operated under various process conditions for various periods of time were studied.

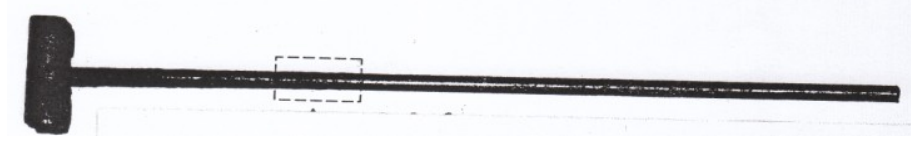

Fig. 2. Appearance of a torque tube and scheme of sample preparation 
The metal of the tubes studied is susceptible to pitting corrosion, intergranular corrosion, and corrosion cracking reaching various depths (see Table 1). This is demonstrated in Figs. 3 and 4. A metallographic study has shown that the alloys in question have an $\alpha$-structure with isolated carbide inclusions of chromium precipitated both at the grain boundaries and in the bulk of the grains (Fig. 5). The majority of austenite grains contain slip bands (Fig. 5) formed upon plastic deformation of the metal during operation indicating a strained state of the structure. The degree of metal deformation varies owing to various levels of stress on the torque tube.
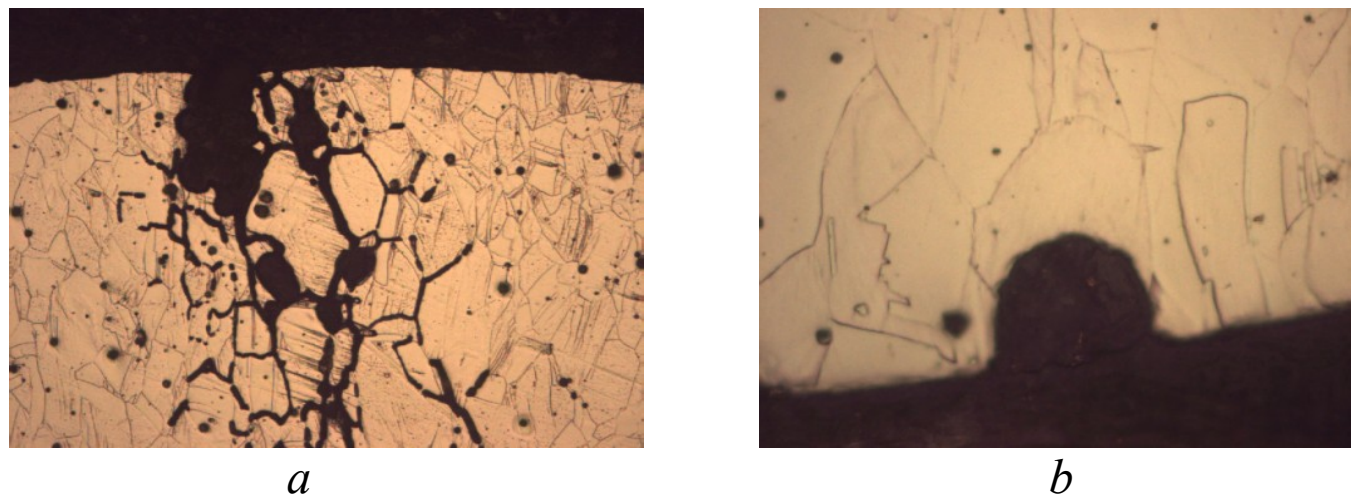

Fig. 3. Mode of failure of torque tubes from Inconel 600 after operation: $a$, in a K-3 column of crude oil distillation plant ELOU-AVT-6. $\times 500 ; b$, in a K-101 column of the LCh-35-11/1000 reforming unit. $\times 200$.
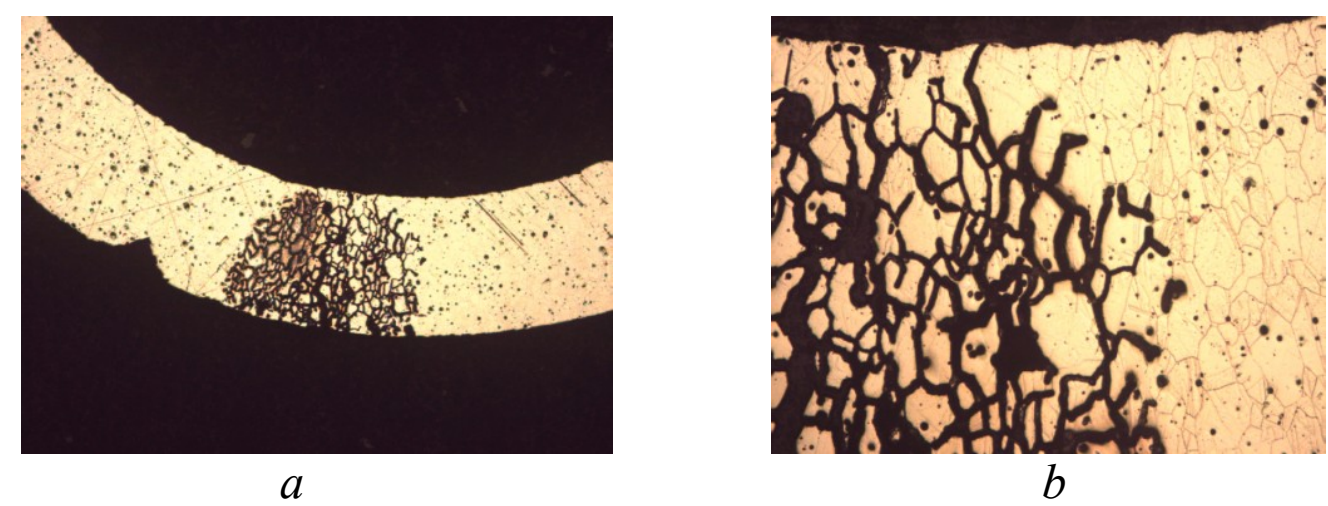

Fig. 4. Intergranular corrosion damage of a torque tube (Inconel) of a level transmitter installed in a K-10 vacuum column of a crude oil distillation plant (ELOU-AVT-6). $a, \times 50$; $b, \times 200$.

The spectrum of grain sizes in the alloys studied is rather wide, i.e., from 3 to 7 units according to GOST 5639-82, which suggests that the torque tube manufacturing technologies and heat treatment modes differ among the tubes. 


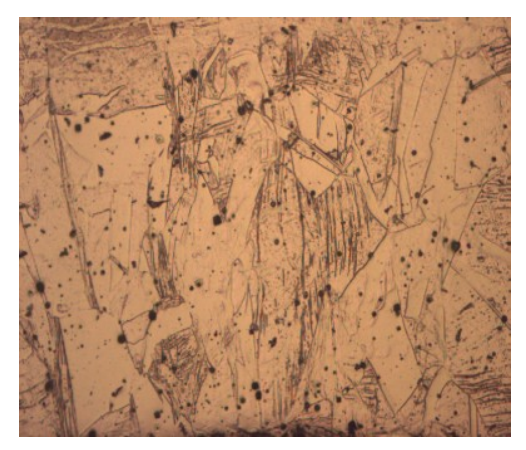

Fig. 5. Structure of Inconel $600 . \times 500$

It is known [6] that the larger the grain size in the metal structure, the faster a crack grows. However, studies have shown that the grain size does not affect considerably the service life of torque tubes, other operation conditions of level transmitters being equal (see Table 2). This allows us to believe that the degradation rate of torque tube metal is primarily determined by the corrosivity of the process fluid at all stages of unit operation, the stress applied to the metal, and the number of stress cycles depending on changes in the process fluid level that the level transmitters measure.

Analysis of corrosion damage cases in level transmitter torque tubes (Fig. 6) made of nickel alloys (Monel, Inconel, Hastelloy) has shown that, though they have high corrosion resistance in the corrosive media that occur in oil treatment, the service life of the tubes does not exceed two years. Premature failures of level transmitters cause a shutdown of the entire vessel.

Currently, there are quite a few chemical and technological measures successfully applied to decrease the corrosion damage of the process equipment at oil treatment plants [7]. However, corrosion protection of level transmitter torque tubes operated in stagnant zones, under elevated stress and in very corrosive media, has almost not been studied. The lack of information in this field required special methods for corrosion protection of metals to be developed.

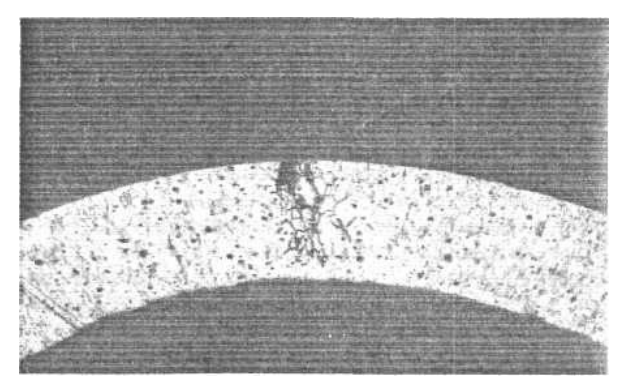

Fig. 6. Corrosion cracking of a torque tube made of Inconel $600 . \times 50$

One of the most technically simple and efficient methods for metal protection from corrosive media under the conditions of possible stagnant zone formation involves the use of preservation materials containing corrosion inhibitors. A lot of publications deal with the inhibiting effect of preservative oils that are especially popular for the temporary protection 
of metal structures from atmospheric corrosion. The use of the broad range of domestic materials is regulated by GOST 9.014 [8]. It has been found that the protective properties of films formed by plastic lubricating materials containing anti-corrosive additives are determined by the existence of a lubricant layer that is applied onto a metal and protects it from corrosion by physical insulation of the metal surface from moisture and oxygen, as well as by the efficiency of inhibition of electrochemical corrosion processes due to adsorption and chemisorption of surface-active compounds on the metal.

We performed the selection of protective preservative formulations for the protection of level transmitters with consideration for their design features and operation conditions. The following requirements for the materials were specified:

- capability to be retained in a preservation zone on inclined elements that are not hermetically sealed, and to create an efficient protective barrier against penetration of corrosive components to the surface;

- high moisture impermeability;

- high thermal stability and high resistance against oxidation;

- semi-liquid consistence for easy penetration of the formulation into the air gap of the level transmitter, followed by its removal to ensure free motion of the tube in the chamber;

- combination of high mechanical strength and elasticity of the film with retention of protective capability under mechanical stress in case of torsion and abrupt temperature fluctuations;

- capability to form non-drying oil films (low-volatility solvent);

- low solubility in oil products (the material should not contaminate oil products).

The components of the coating should have low toxicity, be readily available, and be produced domestically.

The materials that best fit these requirements include VNIINP-207 (GOST 19774-74) and VNIINP-219 (TU 38.101471-74) preservative lubricants and silicone oil, either containing or not containing corrosion inhibitors, e.g., industrial inhibitor M-1 (TU 6-021132-93). Water-resistant lubricants VNIINP-207 and VNIINP-219 are based on a mixture of silicone and industrial oils. These lubricants containing various additives have high performance characteristics, namely, they possess high thermal oxidative stability and can be used at temperatures from $-60^{\circ} \mathrm{C}$ to $+200^{\circ} \mathrm{C}$, but do not contain corrosion inhibitors.

Silicone oils (oligoorganosiloxanes) are colorless, chemically inert, and insoluble in water. In comparison with hydrocarbon oils, organosilicon liquids have very low vaporizability and high decomposition temperature. Owing to their full compatibility with mineral oils, silicone oils are widely used as the base for lubricants with an operating range from -70 to $+150^{\circ} \mathrm{C}$.

The M-1 inhibitor is a salt of cyclohexylamine and $\mathrm{C}_{10}-\mathrm{C}_{13}$ synthetic fatty acids. It is used for the protection of ferrous and non-ferrous metals from atmospheric corrosion. The 
inhibitor is soluble ( 5 mass $\%$ ) in mineral and synthetic oils on heating of the mixture to 60 $70^{\circ} \mathrm{C}$ with vigorous stirring. The volatility of the inhibitor is rather low.

To perform the studies, we prepared formulations based on lubricants of VNIINP brand whose protective properties were enhanced by addition of the M-1 inhibitor (5 mass \%), as well as formulations based on silicone oil of PES-5 brand and M-1 inhibitor. The composition materials were intended for corrosion protection of high-alloy steels and alloys of non-ferrous metals used in level transmitter torque tubes operated under oil processing conditions. The efficiency of the formulations and M-1 inhibitor toward steels is regulated by GOST 9.014 [8]. Therefore, laboratory corrosion tests were carried out by the gravimetric method on Monel specimens of grade NMZhMts 28-2,5-1,5 in hydrocarbon vapors containing corrosive components, viz., hydrogen sulfide and chlorides. The test specimens had the following dimensions: $50 \times 50 \pm 1 \mathrm{~mm}$, thickness $3.5 \pm 0.5 \mathrm{~mm}$. The specimens were prepared for the tests according to GOST 9.054 [9].

The prepared specimens were immersed for $30 \mathrm{~s}$ into the inhibited formulation being studied, then withdrawn, suspended vertically and kept in the air for $24 \mathrm{~h}$ to allow the excess protective formulation to drain down and form a uniform steady-state film. The tests were carried out in desiccators with a capacity of $6.7 \mathrm{~L}$ containing $670 \mathrm{ml}$ of a mixture (1:1) of sulphurous straight-run gasoline, fraction $62-180^{\circ} \mathrm{C}$, and an aqueous $\mathrm{Na}_{2} \mathrm{~S}$ solution (2 $\left.\mathrm{g} / \mathrm{l}\right)$ acidified with $\mathrm{HCl}$ to $\mathrm{pH} 3$. The test specimens were suspended in the gas-air zone using special holders. A desiccator was placed into a heating cabinet and kept for $7 \mathrm{~h}$ at $40^{\circ} \mathrm{C}$, then cooled for $1 \mathrm{~h}$, and kept for $16 \mathrm{~h}$ at $20 \pm 2^{\circ} \mathrm{C}$. The corrosion state was estimated according to GOST 9.311 [10]. The test duration was five cycles. After the test, the protective layer was removed from the specimen surface using a solvent. The specimens were inspected visually to record the state of the surface, then washed, dried, and weighed.

The list of formulations studied and the inhibitor efficiency values determined using the generally accepted formulas are provided in Table 2 .

Based on the data obtained, it has been found that non-inhibited preservative lubricants VNIINP-207 and VNIINP-219 increased the corrosion rate of Monel of NMZhMts 28-2,5-1,5 brand by a factor of 5 and 2.5, respectively, in comparison with the reference. During the test, we noted that the protective coating underwent cracking and corrosion dots (corrosion-damaged sites in the form of black spots) appeared on the metal surface. Even if the M-1 inhibitor was added to the preservative lubricants (VNIINP-207 and VNIINP-219), the corrosion rate was the same as that in the unprotected alloy.

Thus, the lubricants of VNIINP type do not provide corrosion protection of nonferrous alloys and cannot be recommended for corrosion protection of torque tubes under industrial conditions. The most efficient corrosion protection of copper-nickel alloys is provided by 5 mass\% solution of M-1 inhibitor in PES-5 silicone oil (the corrosion inhibition factor was 3.3). 
Table 2. Results of laboratory tests on the efficiency of protective composition materials toward NMZhMts 28-2,5-1,5 alloy (Monel).

\begin{tabular}{|c|c|c|c|}
\hline Composition material & $\begin{array}{l}\text { Mass loss, } \\
\mathrm{g} / \mathrm{m}^{2} \cdot \text { day }\end{array}$ & $\begin{array}{l}\text { Metal and protective } \\
\text { coating damage mode }\end{array}$ & Corrosion inhibition factor \\
\hline $\begin{array}{c}\text { Reference (no protective } \\
\text { additives) }\end{array}$ & 0.001 & Small pits & - \\
\hline $\begin{array}{c}\text { VNIINP - 207, } 50 \% \\
\text { solution in Nefras } 80 / 120\end{array}$ & 0.005 & $\begin{array}{l}\text { General corrosion. The } \\
\text { coating cracked }\end{array}$ & A fivefold corrosion acceleration \\
\hline $\begin{array}{c}\text { VNIINP-219, 50\% } \\
\text { solution in Nefras } 80 / 120\end{array}$ & 0.0025 & $\begin{array}{l}\text { General corrosion. The } \\
\text { coating cracked }\end{array}$ & $\begin{array}{l}\text { A } 2.5 \text {-fold corrosion } \\
\text { acceleration }\end{array}$ \\
\hline $\begin{array}{c}\text { VNIINP-207 + } 5 \text { mass } \% \\
\text { M-1 }\end{array}$ & 0.001 & General corrosion & $\begin{array}{l}\text { General corrosion at the same } \\
\text { level as the reference specimen }\end{array}$ \\
\hline $\begin{array}{c}\text { VNIINP-219 + } 5 \text { mass } \% \\
\text { M-1 }\end{array}$ & 0.001 & General corrosion & $\begin{array}{l}\text { General corrosion at the same } \\
\text { level as the reference specimen }\end{array}$ \\
\hline Silicone oil PES-5 & 0.0005 & $\begin{array}{l}\text { Corrosion spots (pits) near } \\
\text { the face planes; the coating } \\
\text { is clear, no cracking }\end{array}$ & $\sim 2$ \\
\hline $\begin{array}{l}\text { Silicone oil PES-5 + } 5 \\
\text { mass } \% \text { M-1 }\end{array}$ & 0.0003 & $\begin{array}{l}\text { The coating is clear, no } \\
\text { cracking }\end{array}$ & $\sim 3.3$ \\
\hline
\end{tabular}

To estimate the protective efficiency of the formulation under industrial conditions, we carried out pilot testing with witness specimens. Specimens made of various structural materials, with and without a layer of a film-forming composition, were placed into chambers of floater level gages installed in process vessels of oil processing units. The corrosion inhibition factor of PES-5 silicone oil with addition of the M-1 inhibitor ( 5 mass $\%$ ) was $\sim 4$ for carbon steels, $\sim 3.5$ for stainless steels, and $\sim 2$ for NMZhMts 28 2,5-1,5 Monel alloy.

It should be noted that, though the protection of the Monel alloy from general corrosion is not high, the proposed preservative formulation completely suppresses pit corrosion that is one of the main causes of the failure of level transmitter torque tubes (Fig. 7).

The formulation efficiency can be estimated visually by analysis of micrographs of the surface of Monel alloy NMZhMts 28-2,5-1,5 specimens obtained using an Axivert-2 microscope (Fig. 7). The specimen surface without a protective coating was exposed to industrial testing for 3.5 years under real reforming conditions (hydrogen-containing gas with $1.3 \mathrm{~g} / \mathrm{dm}^{3} \mathrm{H}_{2} \mathrm{~S}$, chlorides, unstable hydrogenation product) to undergo considerable pitting corrosion (Fig. 7a). A protective preservative layer of silicone oil containing the $\mathrm{M}$ 1 inhibitor suppresses pitting corrosion almost completely (Fig. 7b). 


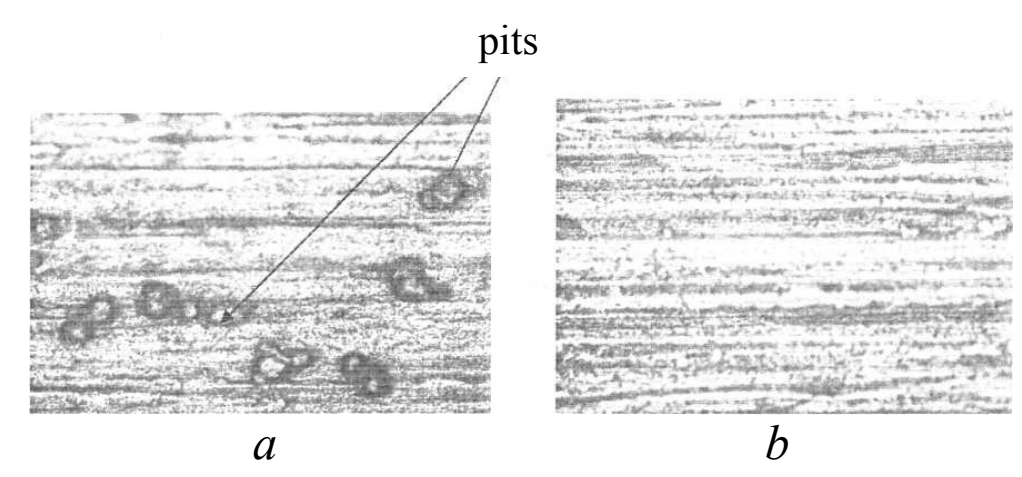

Fig. 7. Surface of specimens from Monel alloy after industrial tests. $\times 200$ : $a$, without protective formulation; $b$, with protective formulation.

Thus, laboratory studies and pilot tests that we performed confirm the efficiency of the selected formulation, that is, $5 \%$ solution of the M-1 inhibitor in silicone oil, for the protection of structural materials used in level transmitters. These results formed the basis for recommendations on the use of the preservative material for corrosion inhibition of the metal of level transmitter torque tubes.

The alloys used in torque tubes are protected from corrosion under industrial conditions as follows: the inhibited formulation heated to $70^{\circ} \mathrm{C}$ is introduced into the space in a level transmitter housing where the torque tube is installed; as a result, the entire surface becomes coated with a layer of the protective formulation. After exposure for $24 \mathrm{~h}$, the excess formulation is drained off (no more than 10 mass $\%$ of the initial amount remains). The eventual coating is a uniform continuous layer.

The level transmitter torque tubes treated with the inhibitor formulation were installed into various vessels in all types of refinery units. The efficiency of the protective inhibited formulation was estimated after operation of the level transmitters for three years. The results of visual examination and technical inspection of level transmitter tubes have shown that the tube surfaces contain nearly no corrosion deposits and the metal has not undergone local corrosion damage. Thus, the inhibitor-containing formulation $(5 \%$ solution of the M-1 inhibitor in silicone oil) ensures a high degree of protection of structural metals from local corrosion damage in oil processing environments.

\section{Conclusions}

1. The materials of torque tubes that we have studied (Hastelloy C-276, Monel 400, and Inconel 600) undergo local corrosion upon exposure to chloro- and sulfur-containing compounds. Hastelloy C-276 (02Kh16N60M16V) and Monel 400 have the highest corrosion resistance under oil processing conditions.

2. The local corrosion damage of the metal in level transmitter torque tubes stems from their design features: existence of stagnant zones and alternate stresses. Damage of the alloys is accelerated due to simultaneous effects of the corrosive components in the process environment along with the formation of concentrated electrolytes and deposits 
of diverse nature on the metal surface, as well as high alternate stress creating a "fresh" surface on the metal stimulating local corrosion processes.

3. In order to reduce the intensity of the corrosion process and enhance the service durability of level transmitter torque tubes, the metal should be protected by inhibitors and the metal quality should be observed in terms of the following indicators:

- microstructure - the real grain size should be no less than 6 units according to GOST 5639 or another international standard;

- chemical composition - the content of chemical elements in the alloys should match the data of the ASTM standard;

- resistance to intergranular corrosion in accordance with GOST 6032 or NACE Standard;

- thermal treatment - quenching by exposure at $1070^{\circ} \mathrm{C}$ followed by cooling in water.

4. The most efficient inhibited preservative material has been selected (5\% solution of the M-1 inhibitor in silicone oil) for the protection of structural materials in level transmitter torque tubes from general and local corrosion operated in chlorine- and sulfur-containing environments.

5. The inhibited preservative material slows down general corrosion and efficiently protects carbon steels, high-alloy steels, and non-ferrous alloys from local corrosion (pitting corrosion and corrosion cracking).

6. The positive results of laboratory studies and pilot tests on corrosion inhibition of structural steels allowed us to recommend this formulation for industrial applications.

7. The practice of level transmitter operation has shown that the inhibited preservative material ( $5 \%$ solution of the M-1 inhibitor in silicone oil) ensures reliable protection of the metal in torque tubes from impact of corrosive components formed in the structural gaps, thus allowing the service life of torque tubes to be extended.

\section{References}

1. H. H. Uhlig and R. W. Revie, Corrosion and Corrosion Control, Wiley-Interscience, 1985.

2. V. V. Burlov, A. I. Altsybeeva and I. V. Parputs, Zashchita ot korrozii oborudovaniya NPZ (Corrosion protection of refinery equipment), St. Petersburg, Khimizdat, 2005 (in Russian).

3. M. A. Streicher, Corrosion, 1976, 32, no. 3, 79.

4. A. V. Ryabchenkov, Korrozionno-ustalostnaya prochnost' stali (Corrosion fatigue strength of steel), Moscow, Mashgiz, 1953 (in Russian).

5. V. V. Burlov, I. V. Parputs and T. P. Parputs, in Protsessy neftepererabotki $i$ neftekhimii (Oil processing and oil chemistry processes), St. Petersburg, GIORD, 2005, 271 (in Russian).

6. Struktura i korroziya metallov (Structure and Corrosion of Metals), Handbook, ed. E. A. Ul'yanina, Moscow, Metallurgiya, 1989 (in Russian). 
7. Neftepererabatyvayushchaya i neftekhimicheskaya promyshlennost' (Oil processing and petrochemical industry), Handbook, Eds. A. M. Sukhotin, A. V. Shreider and Yu. I. Archakov, in 9 volumes, vol. 9, Korroziya i zashchita khimicheskoi apparatury (Corrosion and protection of chemical equipment), St. Petersburg, Khimiya, 1974 (in Russian).

8. Unified System of Protection from Corrosion and Ageing. Temporary Protection of Articles from Corrosion. General Requirements. Consolidated Edition, GOST 9.01478, Moscow, Standartinform, 2005 (in Russian).

9. Unified System of Protection from Corrosion and Ageing. Preservative Materials. Oils, Lubricants and Oil-based Inhibited Thin-film Coatings. Accelerated Methods for Testing Protective Properties, Moscow, Gosstandart, 1976 (in Russian).

10. Unified System of Protection from Corrosion and Ageing. Inorganic Metallic and Nonmetallic Coatings. Methods for Estimation of Corrosion Damage, GOST 9.311-87, Moscow, Gosstandart, 1987 (in Russian). 